\title{
Access to child health services in Orumba North Local Government Area of Anambra State, Nigeria
}

\author{
IJEOMA IGWE, NGOZI I'ARONU and NKECHI ONYENEHO* \\ Department of Sociology/Anthropology, University of Nigeria, Nsukka, Enugu State \\ Nigeria
}

\begin{abstract}
Background: As the world transits from the era of millennium development goals to that of sustainable development goals, an examination of the access to primary health care services in the previous era is germane to adequate planning and delivery of effective service in the emerging era. The objective of this study was determine factors associated with the use of primary health care (PHC) facilities for the health needs of children in Anambra State, Nigeria

Methods: A cross sectional survey of 600 randomly selected mothers (15-49 years) was conducted in Orumba North local government area of Anambra State. An interviewer-based questionnaire, designed to provide information on the socio-demographic characteristics of the respondents as well as their child rearing experiences was used. The questionnaire also provided data on the women's use of immunization services. The perceptions on government health services were also examined to understand how they influence compliance.

Results: More of non-demographic attributes like the mothers' perceptions and past experiences with the health services influenced utilization more than the demographic attributes. Satisfactory experiences with health service influenced utilization $\left(\chi^{2}=168.478 ; p<0.001\right)$. Those with good perception $(95.4 \%)$ used the PHC facilities more $\left(\chi^{2}=198.032 ; p<0.001\right)$.

Conclusion: Irrespective of the socio-demographic backgrounds of the mothers, they all have feelings and react to situations they encounter daily. There is need to improve the experiences mothers get from encounter with the PHC facilities so as to improve on the perception and increase use of the facilities.
\end{abstract}

Keywords: access, child, use, primary health care, Nigeria

\section{Introduction}

Commonly defined as one's ability to obtain and appropriately use good quality health technologies and commodities as and when needed for good health (Ensor \& Cooper, 2004; Frost \& Reich, 2008) effective access to health care services remain elusive to women and children and a challenge to public health in Nigeria. The 2013 Nigerian Demographic and Health Survey revealed that only $25.3 \%$ of children aged $12-23$ months, the age by which they should have received all vaccinations, were fully vaccinated (NPC, 2014). This is only 2 percentage point increase from 2008, where only $23 \%$ received the same vaccinations (NPC, 2009). By 2013, only $51.2 \%$ and $42.1 \%$ received BCG and measles vaccinations, respectively. Fewer children received DPT3 (38.2\%). Comparing uptake of Polio1 (76.5\%) and Polio2 (53.6\%) revealed a 23 percentage point dropout in uptake despite the huge investments of the Global Polio Eradication Initiative to eradicate polio from Nigeria, being the only polio endemic country in Africa (NPC, 2014). Similar dropout was recorded for DPT1 and DPT3, which makes the suboptimal uptake of vaccinations systematic and pervasive rather than circumstantial and antigen related (NPC, 2014).

Similarly, the ownership and use of insecticide treated nets (ITNs) leaves much to be desired. Barely half (55\%) of households surveyed in 2013 had at least one mosquito net and only $50 \%$ had at least one ITN. This leaves over 85 million Nigerians, including children and

\footnotetext{
*Correspondence Email: nkechi.onyeneho@unn.edu.ng
} 
women, without protection from ITNs and exposed to malaria attacks, despite the significant threat of malaria to public health in Nigeria (Idowu et al., 2008; Ajayi et al., 2008; FMOH, 2012; NPC, 2014). At the period for the 2013 Nigeria Demographic and Health Survey only \% of pregnant women slept under net of any type and only $28 \%$ of children under-5 years slept under an ITN. This falls short of the target of at least two ITNs per household, despite the tremendous progress in net production and availability in Nigeria and intensive campaign for net use in households in Nigeria (Okeibunor et al., 2011).

According to Frost \& Reich (2008) the prevailing child mortality rate in developing countries is because many people do not have access to health care services especially the rural dwellers. The low child health status and poor uptake of interventions designed to promote child health in Nigeria are largely attributable to poor antenatal care (ANC) practices, lack of access to and weak health systems (Okeibunor et al., 2011). The situation is further aggravated by poverty and ignorance, which account for women's inability to access critical ANC services and counselling on important safety measures, medicines and other interventions like ITN use (Onokerhoraye, 2000). In many cases, health facilities are few and thinly spread. In the hard to reach rural areas, with difficult terrain and poor road network, modern health facilities are luxuries the dwellers can hardly afford, even when they wish (Okonofua, 2010). Attendance is very poor for a number of personal and logistic issues confronting mothers especially with respect to distance, means of transport and sometimes attitude of health staff (Okonofua, 2010; Okeibunor, et al., 2011).

The foregoing problems and issues tend to suggest that increased child mortality in the country is related to poor access to Primary Health Care services. While the problem may be the same in most Nigerian communities, the actual manifestation and explanatory factors may differ from one locality to another even among social groups within the same society. The objective of this study was determine factors associated with the use of primary health care (PHC) facilities for the health needs of children in Anambra State, Nigeria

\section{Materials and Methods}

\section{Study area}

The study area is located in Anambra State in southeast Nigeria. It had an estimated population of 4, 418,032 in 2006 with an annual growth rate of 2.8\% (NPC, 2006). Anambra State is made up of 21 local government areas which are further divided into 330 political wards and approximately 1,394 communities. There are estimated 717,663 households and 456 health facilities including 21 general hospitals, 232 PHCs, 189 health posts, 11 comprehensive health centres and 3 cottage hospitals. There is also patent medicine vendors (PMVs) scattered in both urban and rural communities. This study was limited to Orumba North Local Government Area (LGA). Going by the 2006 population census, it had a population of 172,405. The 2011 projection gives the LGA a population of 197,932 with a landmass of about $32.4 \mathrm{~m}^{2}$. The choice of Orumba North LGA, a typical rural area, for this study, is because infant and child mortality are higher in the rural areas. For instance, in 2008 child mortality in the rural areas was 106/1000 compared to 58/1000 in the urban communities (NPC, 2009).

\section{Study population}

The target population for this study consisted of all mothers of child bearing age (15-49 years) in the local government area. This constituted $22 \%$ of the total population (NPC, 2006). Thus, the target population was estimated at 43,545. The focus on this segment of the population was justified with the fact that women are closer to their children and known to be the providers of child health in the household. They have also experienced the problem with access to health care due to a complex of factors (Rashid et al., 2001). Using a 51.9\% PHC access rate in the country 
(NPC, 2009) and a confidence interval of $95 \%$ with an estimated 4.0 percentage error margin, a sample size of 599 respondents was computed. The sample size was, however, rounded up to 600 respondents.

A multi-stage cluster sampling procedure, which entails successive selection of community clusters, villages, housing units and respondents, was employed. First the communities were grouped into two clusters $A$ and $B$ based on their proximity to the tarred "Federal" road traversing the LGA. Cluster A was made up of seven communities close to the tarred road, namely Nanka, Oko, Amaokpala, Ndikelionwu, Omogho, Ufuma and Ajalli. Cluster B was made up nine communities remote from the tarred road. They are Ndiowu, Ndiokpalaeke, Ndiokpalaeze, Ndiokolo, Awgbu, Okpeze, Ndiukwuenu, Amaetiti and Awa. Two communities were randomly selected from each cluster. Three villages were randomly selected from each of the four chosen communities, making it 12 villages in all. In each chosen village, all the dwelling units or compounds were numbered, out of which a sample of 50 dwelling units were selected using the systematic sampling technique. In each selected dwelling unit one eligible respondent was selected purposively, taking into account the age and number of children.

\section{Data collection}

An interviewer-based questionnaire, designed to provide information on the socio-demographic characteristics of the respondents as well as their child rearing experiences was used. The questionnaire also provided data on the women's use of immunization services. The perceptions on government health services were also examined to understand how they influence compliance. In doing this, a perception index was constructed using such indicators as how they agreed that the facilities lack personnel, essential medicines and equipment. Other indicators include the attitude of the health workers, their effectiveness, how the staff treated patients among others. The negative statements were scored ' 0 ', if the respondents agreed with them and ' 1 ' if the respondents disagreed. On the other hand, positive statements were scored ' 0 ' or ' 1 ' if the respondents disagreed or agreed respectively. The summation of this gave scores

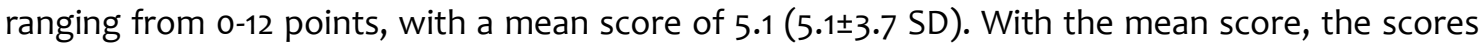
were grouped into good ( $\geq 6$ points) and poor (0-5 points).

\section{Data analysis}

The data were processed and analysed with EPI Info version 6 and SPSS version 19, respectively. Descriptive statistics such as percentages, frequency tables was employed in characterising the respondents. Correlation analyses were also done using Chi-square $\left(\chi^{2}\right)$ and the Pearson's $r$ to illustrate the relationship between certain socio-demographic variables and use of immunization services among the respondents.

\section{Ethical considerations}

The University of Nigeria Teaching Hospital Ethical Review Committee provided the ethical approval. Great care was taken to provide honest and clear information about the objectives of the study and how the results would be used. The principles of informed consent and confidentiality were applied in all areas of the study. Gender issues were taken into consideration during the data collection process. Only female research assistants were engaged to ensure same sex interviews due to cultural sensitivity regarding male-female interaction.

\section{Results}

The women, in this study, were aged between 15 to 49 years with mean age of 35.2 years (35.2 \pm 6.96 SD). Christians of all denominations dominated the sample. Almost eighty-six percent $(85.7 \%)$ of the women enlisted in the study were married and in union. About seven percent 
(6.7\%) of the respondents were single. In terms of educational attainment of respondents, 94.0 percent have had formal education. About a quarter (26.7\%) of the respondents were farmers while another $6 \%$ were unemployed. Others were engaged in some form of paid employment (Table 1).

Table 1: Socio-demographic characteristics of the respondents

\begin{tabular}{|c|c|c|c|}
\hline Characteristic & Response & Frequency & Percentage \\
\hline \multirow[t]{7}{*}{ Age in years } & $15-19$ & 5 & 0.85 \\
\hline & $20-24$ & 21 & 3.5 \\
\hline & $25-29$ & 107 & 17.8 \\
\hline & $30-34$ & 156 & 26.0 \\
\hline & $35-39$ & 149 & 24.8 \\
\hline & $40-44$ & 87 & $14 \cdot 5$ \\
\hline & $>45$ & 75 & 12.5 \\
\hline \multirow[t]{4}{*}{ Marital status } & Married & 514 & 85.7 \\
\hline & Single & 40 & 6.7 \\
\hline & Separated/Divorced & 5 & 0.8 \\
\hline & Widowed & 41 & 6.8 \\
\hline \multirow[t]{6}{*}{ Occupation } & Farming & 160 & 26.7 \\
\hline & Trading & 209 & 34.8 \\
\hline & Business & 103 & 17.2 \\
\hline & Artisan & 57 & $9 \cdot 5$ \\
\hline & Civil service & 35 & 5.8 \\
\hline & Unemployed & 36 & 6.0 \\
\hline \multirow[t]{4}{*}{ Education } & No formal education & 36 & 6.0 \\
\hline & Primary school & 224 & 40.7 \\
\hline & Secondary school & 273 & $45 \cdot 5$ \\
\hline & Tertiary & 47 & 7.8 \\
\hline \multirow[t]{5}{*}{ Religious affiliation } & Catholic & 252 & 42.0 \\
\hline & Anglican & 222 & 37.0 \\
\hline & Pentecostal & 118 & 19.7 \\
\hline & Islam & 3 & 0.5 \\
\hline & Traditional Religion & 5 & 0.8 \\
\hline \multirow[t]{6}{*}{ No. of years lived in study community } & $<1$ & 5 & 0.8 \\
\hline & $1-4$ & 52 & 8.7 \\
\hline & $5-9$ & 60 & 10.0 \\
\hline & $10-14$ & 89 & 14.8 \\
\hline & $15-19$ & 65 & 10.8 \\
\hline & $>20$ & 329 & 54.8 \\
\hline
\end{tabular}

Malaria was the commonest health problem confronting children in the study communities. This was mentioned by 83.0 percent of the respondents. Fever was the second most common health problem among children mentioned by 62.2 percent of the respondents in all the communities studied. About a third (33.3\%) of the respondents mentioned spiritual attack while another 20.2 percent of the respondents mentioned cough as a common health problem among children in the communities under study.

Taking the preponderance of mention as indication of importance of each health problem (Figure 1) malaria, fever and spiritual attack are the first, second and third most important health problems that confront children in the communities. On the other hand, polio was the least disturbing health problem of children in the communities. 
Table 2: Factors associated with use of primary health care (PHC) centres for child health needs

\begin{tabular}{|c|c|c|c|c|c|}
\hline Factor & Category & Number & \%Use of PHC & $x^{2}$ & P value \\
\hline \multirow[t]{2}{*}{ Age } & Young mother(15-29) & 133 & 68.4 & 0.334 & 0.320 \\
\hline & Older mothers(30-49) & 467 & 65.7 & & \\
\hline \multirow[t]{2}{*}{ Marital Status } & Ever married & 40 & 67.5 & 0.026 & 0.511 \\
\hline & Never married & 560 & 66.3 & & \\
\hline \multirow[t]{2}{*}{ Ever attended School } & Yes & 564 & 66.0 & 0.595 & 0.282 \\
\hline & No & 36 & 72.2 & & \\
\hline \multirow[t]{2}{*}{ Work for pay? } & Yes & 404 & 61.6 & 12.231 & $<0.001$ \\
\hline & No & 196 & 76.0 & & \\
\hline \multirow[t]{2}{*}{ Religion } & Orthodox Christian & 474 & 62.4 & 15.263 & $<0.001$ \\
\hline & Others & 126 & 81.0 & & \\
\hline \multirow[t]{2}{*}{ Use health facility } & Yes & 491 & 75.6 & 103.032 & $<0.001$ \\
\hline & No & 109 & 24.8 & & \\
\hline \multirow{2}{*}{$\begin{array}{l}\text { Experience with health } \\
\text { service }\end{array}$} & Satisfied & 289 & 92.4 & $169 \cdot 478$ & $<0.001$ \\
\hline & Dissatisfied & 311 & 42.1 & & \\
\hline \multirow{2}{*}{$\begin{array}{l}\text { Perception of health } \\
\text { service }\end{array}$} & Good(6-12) & 280 & 95.4 & 198.032 & $<0.001$ \\
\hline & Poor(0-5) & 320 & 40.9 & & \\
\hline
\end{tabular}

On where children are taken for their health needs in the communities, the results revealed that mothers have various options. These include primary health care (PHC) centres and medicine stores. Other options included traditional and spiritual healers. Two-thirds of the respondents (66.3\%) visited the primary health centres for child health requirements, while $36.2 \%$ indicated that they resorted to patent medicine vendors to seek solutions for their children's illness. Others went to traditional healers (2.3\%) and spiritual healers (0.8\%).

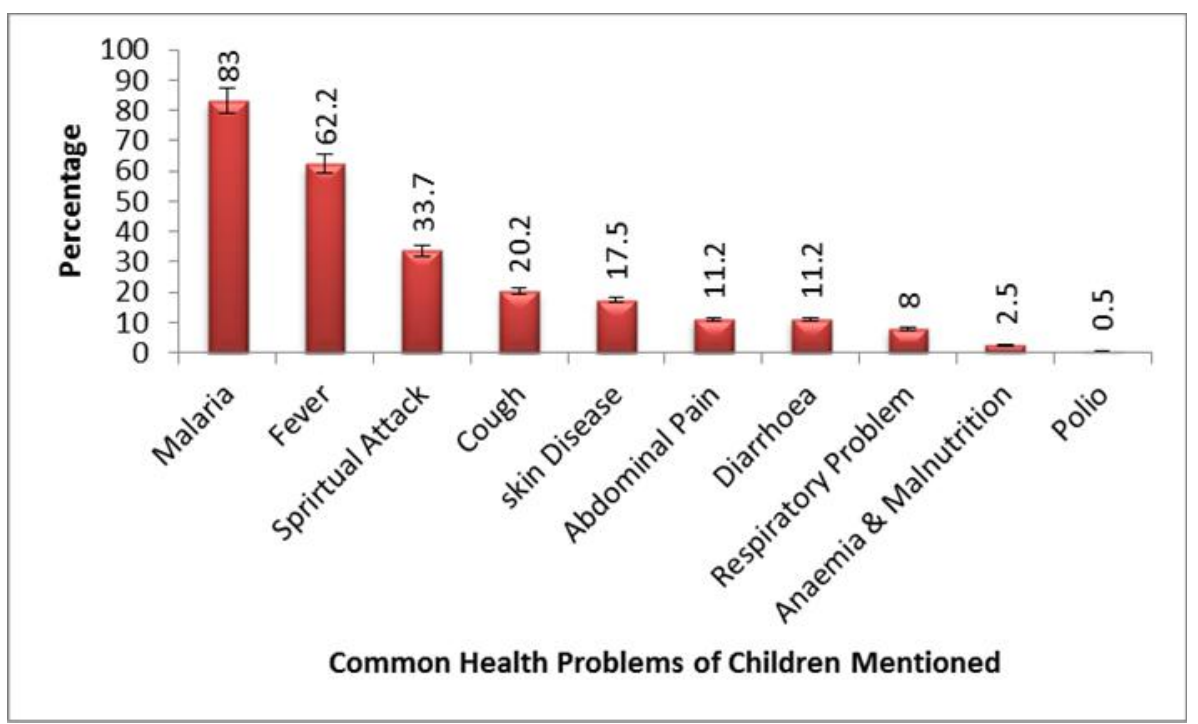

Figure 1: Percentage distribution of respondents on common child health problems

Utilization of PHC facility was more among younger women in the child bearing ages of 15-29 years (68.4\%), albeit, the difference between this group and the older women in ages of 30-49 years $(65.7 \%)$ was not statistically significant $\left(\chi^{2}=0.334 ; p=0.320\right)$. The same was the case when the results were compared across marital and educational statuses of the women. Women however differed significantly $(p<0.001)$ when their religious affiliation and employment statuses were involved. A comparison across other characteristics also showed some significant differences. For instance, utilization was more among those who used the government health facilities for their own health needs (75.6\%) than those who sought health care from other 
sources $(24.8 \%)\left(\chi^{2}=103.032 ; p<0.001\right)$. Utilization of primary health care centres for child health needs was more among those who had satisfactory experiences (92.4\%) than those who were dissatisfied with their experiences $(42.1 \%)$ of the health services $\left(\chi^{2}=169.478 ; p<0.001\right)$.

A comparison of the utilization of primary health care centres for child health needs across the perception scores revealed more utilization among those with good perception (95.4\%) than those with low perception (40.9\%). This difference was statistically significant $\left(\chi^{2}=198.032 ; \mathrm{p}<0.001\right)$.

Table 3: Key factors associated with use of primary health care centres for child health

\begin{tabular}{lllllll}
\hline Key Factors & B & S.E. & Wald & df & Sig. & Exp (B) \\
\hline Age & -0.157 & 0.280 & 0.316 & 1 & 0.574 & 0.854 \\
Ever married & -0.412 & 0.457 & 0.813 & 1 & 0.367 & 0.662 \\
Being in paid employment & -0.471 & 0.259 & 3.314 & 1 & 0.069 & 0.624 \\
Ever being to school & 0.102 & 0.512 & 0.040 & 1 & 0.841 & 1.108 \\
Christianity & -0.717 & 0.309 & 5.364 & 1 & 0.021 & 0.488 \\
Ever used health facility & 0.868 & 0.442 & 1.535 & 1 & 0.215 & 1.729 \\
Experience with health service & 1.220 & 0.320 & 14.503 & 1 & 0.000 & 3.388 \\
Perception of health service & 2.225 & 0.365 & 37.166 & 1 & 0.000 & 9.256 \\
Constant & 0.229 & 0.774 & 0.088 & 1 & 0.767 & 1.258 \\
\hline
\end{tabular}

Key: B=Beta coefficient; S.E. =Standard Error; Wald=Abraham Wald test of true association between dependent and independent variables; $\mathrm{df}=$ degree of freedom; Sig=level of significance; $\operatorname{Exp}(B)=$ Exponentiation of the $B$ coefficient

Further analysis was done combining the demographic and some other relevant factors from the questionnaire in a logistic regression to ascertain the independent contribution of each factor to compliance. The resulting analysis found some factors that were associated with compliance to the recommended required regimen of the existing vaccines (Table 3). Age showed a statistically significant association with compliance. It showed that older mothers complied more. One (religion) out of five demographic attributes and two (experience with; and perception of health service) out of the three non-demographic attributes of the women were significantly associated with utilization of primary health care centres for child health care needs in the communities. Those who affiliated to non-orthodox religious groups, who have had satisfying experiences with the health service and good perceptions of the health services, used the primary health care centres more for the health needs for their children.

\section{Discussion}

The Alma Ata Declaration in 1978 ushered in the primary health care (PHC) system as the foundation for health care provisioning (Okeibunor et al., 2015; Lawn et al., 2008; Maclean et al., 2004). The subsequent United Nations declaration of the Millennium Development Goals, hinged the realization of the health related targets on the functionality of the PHC of member states (Okeibunor et al., 2015). African Health Ministers at a meeting in Lusaka in 1985 resolved to strengthen their national health systems using the PHC approach (Monekosso, 1989; Okeibunor et al., 2015). The guiding principles were community participation and empowerment for sustainable health programmes as well as collaboration between the community and the usual health services, leading to strengthening of the national health system, which thus becomes community-appropriate (Okeibunor et al., 2015). Communities were expected to use and support the PHC as the first port of call for health needs while the secondary and tertiary health institutions serve as centres to receive cases referred from the lower facilities.

However, with the weakening of other institutions in the country, following incessant change in government and governance ideologies came very tenuous commitment to health care in the country generally and indeed PHC and health care in the communities. It is not surprising therefore that in this study the people would rather go to other sources for the health needs of 
their children instead of using the primary health care facilities closest to them. The women relied on patent medicine vendors and private for profit hospitals in their communities. The people are dissatisfied with the primary health care centres. This has been confirmed in other studies. For instance a study in the management of tuberculosis highlighted given the attitude of health workers in public health facilities, care givers and patients opt for patent medicine vendors and private for profit hospitals in the Southern States of Nigeria covered under the German Leprosy and Tuberculosis Relief Foundation (Onyeneho et al., 2010; 2011)

The study confirmed findings from other studies on the existence of factors, beyond availability, to influence access of health interventions. Access, here, is defined not just as availability of health services but also proper utilization (Frost \& Reich, 2008). According to Roberts et al. (2008), “... utilization is only partially a reflection of effective availability, as patients may choose not to use services, even if they are available". In other words, low use of the health services is a reflection of patient choice, which is often influenced by their perception of the services. This also agrees with earlier studies on efforts to change health behaviours (Frank, 1987; Okeibunor et al., 2007). In some studies it was concluded that health seeking behaviours are poor not because of lack of knowledge of existence of improved life-saving technologies but because of prevailing perceptions about these life-saving technologies (Frank, 1987; Okeibunor et al., 2007). In this study, we found that a number of factors constrain the utilization of primary health facilities. These factors are aptly captured in the health belief models (Rosenstock, 1974), but for specific clarities we shall look at them hereunder.

The effects of the perceptions and experiences of the mothers on uptake of health services for these children in large part conform to the Health Belief Model (HBM) as tested against compliance by others (Austin et al., 2002; Russell et al., 2006). HBM in simplest terms takes a two-pronged look at the likelihood of complying with a recommended behaviour. While one set of factors consider threat perceptions of the disease in question consisting of perceived susceptibility and seriousness (severity), the other looks at cost of the proposed action, in this case the satisfaction or otherwise of the mothers. Other studies have demonstrated the influence of encouragers/discouragers to compliance (Finney \& lannotti, 2003; Farquharson et al., 2004; Orensky \& Holdford, 2005). Russell et al. (2006) have also interrogated the factor of barriers to behaviour, as is the case with the mothers' dissatisfying experiences with the health service.

The main limitation of the study was the absence of health workers in the health centres. Efforts to get health workers in some of the health centres were unsuccessful. The study would have benefited from the views of the health workers on the people's attitude to child immunization as well as suggestions on how to ensure every child is fully immunized, with existing vaccines against childhood illnesses. It will thus be necessary to suggest another study to cover this gap in information.

In conclusion this study has identified some of the demographic, cognitive and perceptual factors that are associated with utilization of primary health care facilities for child health needs. This is important in designing programmes to increase utilization of the primary health care centres where preventive services and commodities are often located within the health system. Training of health workers to improve on the experiences and perception of mothers about the health service is urgently needed, and prompts and encouragers for desired behaviour among mothers.

\section{References}

Ajayi, I.O., Falade, C.O., Olley, B.O., Yusuf, B., Gbotosho, S., lyiola, O., Olaniya, O., Happi, C., Munguti, K \& Pagnoni, F. (2008) A qualitative study of the feasibility and community 
perception on the effectiveness of artemether-lumefantrine use in the context of home management of malaria in South-west Nigeria. BMC Health Science Research 8:119.

Austin, L.T., Ahmad, F., McNally, M.J. \&, Stewart, D.E. (2002) Breast and cervical cancer screening in Hispanic women: a literature review using the health belief model. Women's Health Issues 12, $122-8$.

Ensor, T. \& Cooper, S. (2004) Overcoming barriers to health services access and influencing the demand side through purchasing. Washington, DC: The international bank for reconstruction and development. Available: http://www.worldbank.org/404_response.htm

Farquharson. L., Noble, L.M., Barker, C. \& Behrens, R.H. (2004) Health beliefs and communication in the travel clinic consultation as predictors of adherence to malaria chemoprophylaxis. British Journal of Health Psychology 9, 201-217.

Finney, R.L.J. \& Iannotti, R.J. (2003) Health beliefs, salience of breast cancer family history, and involvement with breast cancer issues: adherence to annual mammography screening recommendations. Cancer Detection Prevention 27, 353-359.

FMOH (2012) National integrated community case management of malaria. National Malaria Control Programme, Federal Ministry of Health, Abuja, Nigeria.

Frost, L.J. \& Reich, M.R. (2008) Access: How do good health technologies get to poor people in poor countries? Cambridge, Massachussetts, Harvard Centre for Population and Development Studies. Available: www.accessbook.org/downloads/AccessBook.pdf

Idowu, O.A., Mafiana, C.F. \& Sotiloye, D. (2008) Traditional birth home attendance and its implications for malaria control during pregnancy in Nigeria. Transactions of the Royal Society of Tropical Medicine and Hygiene 102, 679-684.

Igwe, P.C., Ebuchi, O.M., Imem, V., \& Afolabi, B.M. (2007) Effects of the use of insecticide treated bednets on birth outcomes among primigravidae in a per-urban slum settlement in South East Nigeria. South African Family Practice 49, 15.

Lawn, J. E., Rohde, J., Rifkin, S., Were, M., Paul, V.K. and Chopra, M. (2008) Alma-Ata: Rebirth and Revision 1. Alma-Ata 30 Years On: Revolutionary, Relevant, and Time to Revitalise. Lancet 13372 (9642): 917-27.

MacLean, L. M., Meyer, M., and Estable, A. (2004) Improving Accuracy of Transcripts in Qualitative Research. Qualitative Health Research 14, 113-123.

Monekosso, G. L. (1989) Accelerating the Achievement of Health for All African: The Three-Phase Health Development Scenario. Brazzaville, Republic of the Congo: WHO Regional Office for Africa.

NPC (2012) Nigeria Malaria Indicator Survey 2010. National Population Commission and ICF International, Abuja, Nigeria. Available: http://dhsprogram.com/pubs/pdf/MIS8/MIS8.pdf

NPC (2014) Nigeria Demographic and Health Survey 2013. National Population Commission and ICF International, Abuja, Nigeria, and Rockville, Maryland, USA. Available: https://dhsprogram.com/pubs/pdf/FR293/FR293.pdf

NPC (2006) National and State Population and Housing Tables: Priority Table 1\&43. National Population Commission, Abuja, Nigeria.

NPC (2009) Final Report of 2008 Nigerian Demographic and Health Survey. National Population Commission \& ICF Macro, Abuja. Available: http://dhsprogram.com/pubs/pdf/FR222/FR222.pdf

Ogunlade, S. \& Mazue, C. (1987) Infant and childhood mortality and socio- economic factors in Africa. Addis Ababa, Ethiopia: UNECA. Available: http://www.popline.org/node/364032

Okeibunor, J.C., Onyeneho, N.G. \& Chukwu, J.N. (2007) Post E. Barriers to care seeking in directly observed therapy short-course (DOTS) clinics and tuberculosis control in Southern Nigeria: A qualitative analysis. International Quarterly of Community Health Education 27, 23-37. 
Okeibunor, J.C., Orji, B.C., Brieger, W., Ishola, G., Otolorin, E.O., Rawlins, B., Ndekhedehe, E.U., Onyeneho, N. \& Fink, G. (2011) Preventing malaria in pregnancy through communitydirected interventions: evidence from Akwa Ibom State, Nigeria. Malaria Journal 10:227.

Okeibunor, J., Njepuome, A.N., Nwaorgu, O.C., Onyeneho, N.G., Amazigo, U.V. (2015) Community perception of health services in South East Nigeria: A reflection of health system governance in Nigeria. In Reich M.R., and Takemi K. (eds). Governing health systems for nations around the world. Brookline MA, Lamprey \& Lee, 138-176pp.

Okonofua, F. (2010) Reducing maternal mortality in Nigeria: An approach through policy research and capacity building. African Journal of Reproductive Health 14, 9-13.

Onokerhoray, G. (2000) Health and Family Planning Services in Nigeria. Benin City: Social Science Series for Africa.

Onyeneho, G.N. \& Chukwu, J.N. (2010) Is there a role for patent medicine vendors in tuberculosis control in Southern Nigeria. Journal of Health Population and Nutrition 28, 567-577.

Onyeneho, G.N. \& Chukwu, J.N. (2011) Role of traditional healers and tuberculosis control in Southern Nigeria. International Quarterly of Community Health Education 31, 187-202.

Orensky, I.A. \& Holdford, D.A. (2005) Predictors of noncompliance with warfarin therapy in an outpatient anticoagulation clinic. Pharmacotherapy 25, 1801-1808.

Rashid, S., Hadi, A., Afsana K. \& Bequm, A. (2001) Acute respiratory infections in rural Bangladesh: Cultural understandings, practice and the role of mothers and community health volunteers. Tropical Medicine \& International Health 6, 249-255.

Roberts, M.J., Hsiao, W., Berman, P. \& Reich, M.R. (2008) Getting Health Reform Right: A guide to improving performance and equity. New York, Oxford University Press

Rosenstock, I. (1974) Historical Origins of the Health Belief Model. Health Education Monographs 2 (4).

Russell, K.M., Perkins, S.M., Zollinger, T.W. \& Champion, V.L. (2006) Sociocultural context of mammography screening use. Oncology Nursing Forum 33, 105-112. 